\title{
From Understudy to Leading Star: the Future Role of Impact Assessment in Food Aid Programmes
}

\author{
Simon Maxwell
}

\section{Introduction ${ }^{1}$}

Food aid is both over-studied and under-studied: there is a disproportionately large literature on food aid compared to other aspects of aid (and, indeed, compared to many other aspects of development), characterised by its singular failure to reach any kind of agreement on the fundamental issues. ${ }^{2}$ These include whether there should be food aid at all, the most appropriate commodities to be used, the types of use to which food aid should be put, and the criteria for deciding who should receive it, on what scale, and under what conditions.

At the same time, food aid has been inadequately studied in many respects, notably in terms of its impact on recipient countries. Despite some early pioneering work [Ginor 1963; Aktan 1965; Coutsoumaris et al 1965], the paucity of impact studies has been an important limitation on attempts to improve the planning and programming of food aid and has been reflected in the frustration felt by many observers attempting impartial evaluation [eg Maxwell 1978a, $1978 \mathrm{~b}$; Schuh 1979]. The validity of this general observation is not contradicted by the existence of competent individual case studies [eg Grissa 1973, Stevens 1979]. Fortunately, there is increasing awareness of the need for better impact assessment, not only to make sense of the acrimonious debate surrounding food aid, but also to improve the management of programmes which now cost some US $\$ 2,600 \mathrm{mn}$ a year (1980) and account for around 10 per cent of total official development assistance [OECD 1981].

It is the purpose of this article to help clarify the issues surrounding impact assessment and in particular to look at the practical problems attendant upon any attempt to improve the monitoring and evaluation of food aid impact. Section II looks in more detail at the

${ }^{1}$ The author is indebted to Shirley Downs for her help in the preparation of this paper and is pleased to acknowledge the comments of other colleagues. Responsibility is his alone.

${ }^{2}$ For a general review of the literature on food aid see Maxwell and Singer [1979]. A recent, and polemical, analysis is provided by Jackson [1982]. role and function of impact assessment and distinguishes it from other monitoring and evaluation functions. Section III turns from general concepts to the particular problems of assessing the impact of food aid. In Section IV a method is proposed for designing systematic impact assessment which at the same time economises on the scarce resources of time, money and organisation. Finally, Section $\mathrm{V}$ draws the argument together and suggests what might be done next by food aid donors and recipients interested in a better understanding of the impact of their efforts.

As a preliminary to all this, and by way of justification, two anecdotes will be recounted, loosely based on fact. Both concern large, respectable and generally competent food aid agencies anxious to establish the impact of their programmes. The first is concerned with 'programme' food aid, delivered to recipient countries in bulk, for sale on the open market as a resource to permit faster growth; and the second concerns food aid delivered to specific projects for direct distribution to recipients on food for work sites or supplementary feeding programmes.

In the first case, the Agency commissioned an evaluation study which would look at the impact of its programme, and allowed for less than one month's fieldwork in the country concerned. The evaluation team of two people expected to find that the proceeds of food aid sales had been paid into a separate government account or 'counterpart fund', and that particular additional projects would have been funded from this account: these projects could then be counted as the benefit of the food aid. Once they arrived in the country, however, a number of disturbing factors became clear. The first was, perhaps unsurprisingly, that no counterpart fund existed and that all the funds raised by selling food aid had been absorbed into the consolidated fund. This meant that it was in practice impossible to identify any particular projects. The government did, however, claim to have funded certain projects with food aid resources and these were shown to the mission. But it was apparent to the mission that these were high priority projects that would have been funded anyway as part of the 
country's food security system and that they were faced with a clear case of 'fungibility', in which it was impossible for them to identify any particular additional activities made possible by food aid. As they considered this, they also stumbled over a further problem which was that the particular projects that might or might not have been financed by a counterpart fund were a very poor proxy for the effect that food aid might have on growth. In a narrow sense this was because the food had been sold at highly subsidised prices so that the counterpart fund, had it existed, would have been very much smaller than the notional value of the food aid. And in a broader sense, it was because the macro-economic contribution of the food aid transfer as a foreign exchange supplement, was probably greater for this country experiencing a severe balance of payments crisis than the simple measure of the value of food sold. By the time that this analysis had been completed, the month was up and it was time for the mission to return to headquarters with only a very vague idea as to the possible developmental effect of the food aid.

The second evaluation team faced similar problems, although it was working for a different agency on a different type of project. Its task was to assess the impact of a food for work project, and it too was given less than a month in the recipient country in order to collect data and reach its major conclusions. On arriving in the country the mission found that almost no information existed either about the socioeconomic status of the participants in the food for work scheme or about the costs and benefits of the public works on which hey were engaged. It quickly discovered that the 'project' which had been funded by the agency was in fact a highly diverse set of essentially separate projects in different parts of the country, where ecological and social conditions were quite different. And it also found that apart from the direct, internal costs and benefits of the project, there were also significant indirect or external effects which needed to be studied, particularly with respect to the market for local produce and to the supply and demand for labour in the project areas. Again, the mission was forced to return with only a hazy notion of the true situation regarding the project and to form its conclusions on this basis.

These two case studies share a number of characteristics. In both, the agency lacked a model of what the impact of its food aid might be, so that, even at quite a late stage of ex post evaluation, disagreements could arise as to what constituted a benefit. Furthermore, in both cases, evaluation missions were expected to assess the impact of food aid programmes in situations where no base line data had been collected and where no systematic procedure had been set up for monitoring the impact of the project. And in both cases, the missions were 'rush jobs', mounted at very short notice and at considerable cost, allowed very little time for field work and were subject to great pressure to meet deadlines for handing in their reports. The result was the same in both cases: in a sense, an opportunity missed. It is in order to permit such opportunities to be seized more forcefully in the future that we proceed with the detailed discussion below.

\section{Role and Functions of Impact Assessment ${ }^{3}$}

It is necessary to distinguish impact assessment from the other types of monitoring and evaluation that takes place, or ought to take place, whenever development activities are undertaken. In this, as in other cases, the food aid specialist can safely draw on a wider literature dealing with the basic issues. This kind of connection is not made often enough in food aid studies where, for example, food for work is often approached as if there did not already exist a considerable literature on public works in general. In the case of monitoring and evaluation systems, a considerable literature does exist, principally, but not exclusively, concerned with the monitoring and evaluation of agricultural and rural development projects [eg Clayton and Petry 1981].

Two important distinctions are made in the literature. The first is broadly between the 'efficiency' of projects and their 'effectiveness': that is between whether inputs are delivered at the right time and place and in the right quantities, and are then combined effectively; and whether or not the outcomes are sat isfactory. The second distinction is between 'monitoring' (defined by Clayton [1981] as the 'process of measuring, recording, collecting, processing and communicating information to assist project management decision making') and 'evaluation' ('the comparison of actual project operation, performance, and impact with those originally specified or planned').

In general it can be said that management tends to place greater emphasis on monitoring than it does on evaluation. In the case of food aid programmes it is probably true to add that rather little emphasis is placed on either of these, especially when it comes to committing resources in the field.

The monitoring and evaluation of impact, of course, raises much wider problems than those encountered in measuring operation or performance. In the first place, the necessary indicators tend to be found outside rather than inside the particular activity; and

\footnotetext{
${ }^{3}$ This section draws heavily on the excellent introduction to monitoring and evaluation problems provided by Clayton [1981].
} 
external indicators are both harder to measure than internal ones and less directly under the control of management. The time dimension is also different when it comes to measuring project impact: the data may be required at less frequent intervals but is likely to take longer to collect. Furthermore, the number and range of skills required will be much greater when it comes to impact assessment so that it may be more difficult to design and maintain an adequate monitoring and evaluation machinery.

The most obvious role for monitoring and evaluation, whether of impact or of other elements, is as a management tool which permits correction to be made to the activity during execution. It might be found, for example, that a nutrition intervention programme is meeting all its targets in terms of food deliveries and food consumption, but that the expected improvement in nutritional standards is failing to materialise, perhaps because of an unexpectedly high incidence of intestinal parasitosis. The managers of the nutrition intervention would need to have this kind of feedback on the impact of the project and would want to take some corrective action, perhaps the introduction of a parallel health programme.

At another fairly straightforward level, monitoring and evaluation of the impact of development activities can be used ex post in order to improve the planning of future projects. To follow the example used above, it might be decided that in all future cases nutrition intervention programmes should be planned with greater attention to the health status of the population and that funds should be provided for a health programme whenever this was considered necessary.

The distinguishing characteristic of monitoring and evaluation expenditures is that they are directed to policy. Data collection and analysis are not cost free - indeed they may be extremely costly - so that it is important to control cost effectiveness and to make sure that policy mechanisms are sensitive to the receipt of information. There is no point in undertaking monitoring and evaluation if all the decisions to be made are in fact decided on quite other grounds.

\section{The Monitoring and Evaluation of Food Aid}

If there is a need for better impact assessment and if it can only be met by improving monitoring and evaluation systems, what precisely should be monitored and what kind of organisation is necessary to collect the data? The main difficulty lies in the diffuse nature of the effects of food aid and in the complexity of the models required to capture all its possible direct and indirect effects. Two examples will help to draw attention to the range of data required and serve to underline the dimension of the monitoring problem. The general point is that, at least in principle, the monitoring requirement is extremely large for measuring the impact of all types of food aid. This means that there is a particular need to consider the cost effectiveness of monitoring and ensure its close relation to policy.

\section{Food for work projects}

Take first the case of a food for work project and consider the task of forecasting, monitoring and evaluating its impact. Clearly a set of hypotheses is needed about the expected impact of the project, which can then be tested.

The literature on public works, of which food for work is a special case, suggests that the most appropriate format for evaluation is a series of cost-benefit studies, both at the level of the individual participant or beneficiary and at the level of the village, region or country as a whole [Maxwell 1978b; Burki et al 1976]. The cost-benefit approach allows a measure of the impact of the project to be compared with the cost of achieving it; and, because the cost and benefits do not occur simultaneously, it provides a framework within which cost and benefit streams can be compared over time. Furthermore, well established methods exist for bridging the gap between 'private' cost benefit analysis, conducted in market prices, and 'social' cost benefit analysis, conducted in national accounting or shadow prices; in addition, methods exist, at least in theory, for the valuation of such social benefits as better nutrition, greater employment or more equal income distribution [Squire and Van der Tak 1975].

Direct costs and benefits of a food for work project are the easiest to identify. Costs will include labour, materials and supervision; benefits may include such items as lower transport costs, greater production or a flow of benefits from fish tanks, forestry or other production activities. All these can be estimated in advance and compared with the eventual outcome. A series of cost-benefit studies will be needed, beginning with the costs and benefits for individual families or landowners participating in the scheme and building up to a whole-project analysis [cf Costa 1978].

The data requirements for this kind of analysis are large. In the case of farmers receiving assistance with terracing or land development, for example, the starting point would be a description of the existing farm system in sufficient detail to permit calculation of existing family income. It would then be necessary to forecast the effect of development activities on such aspects as yield over time and to build into the analysis a detailed forecast of future labour and input 
requirements, so as to calculate a revised net farm income after the completion of land development works. This would permit a comparison of the 'with' and 'without' project situation, with the costs and benefits being built up over time in order to permit a discounted cash flow analysis. This analysis should of course be prepared before the project begins in order to test its economic feasibility, and should then be recalculated both during the course of the project and after its completion in order to ensure that the intended effects have been achieved. If different categories of farm are participating in the scheme it is necessary to repeat the analysis for different 'model' farms and to build these up in order to form a picture of the benefits of the project as a whole.

The kind of information required is not normally available in published form and is in any case subject to problems of estimation and error. It will therefore normally be necessary for project authorities to generate the data themselves through farming system surveys, and to repeat surveys at later stages in the monitoring and evaluation process. Physical and agronomic information will also be required which can often only be obtained by investigation of individual farmers' fields: needless to say this may take some years, although it may be thought sufficient to begin with preliminary estimates [for further discussion see FAO 1981a; Wiggins and Palma 1980].

However, as noted above, the measurement of the direct costs and benefits is only part of the analysis required and in some ways the easier part. An important place has been given in the literature to a discussion of indirect effects, and two of these in particular are worth examining. The first is the provision of employment and improved nutritional status, which are often included as objectives of public works schemes [Arlès 1966; Stevens 1979]. For this impact to be measured, the existing employment and nutritional status must be recorded and a means of measuring the changes in nutrition and employment

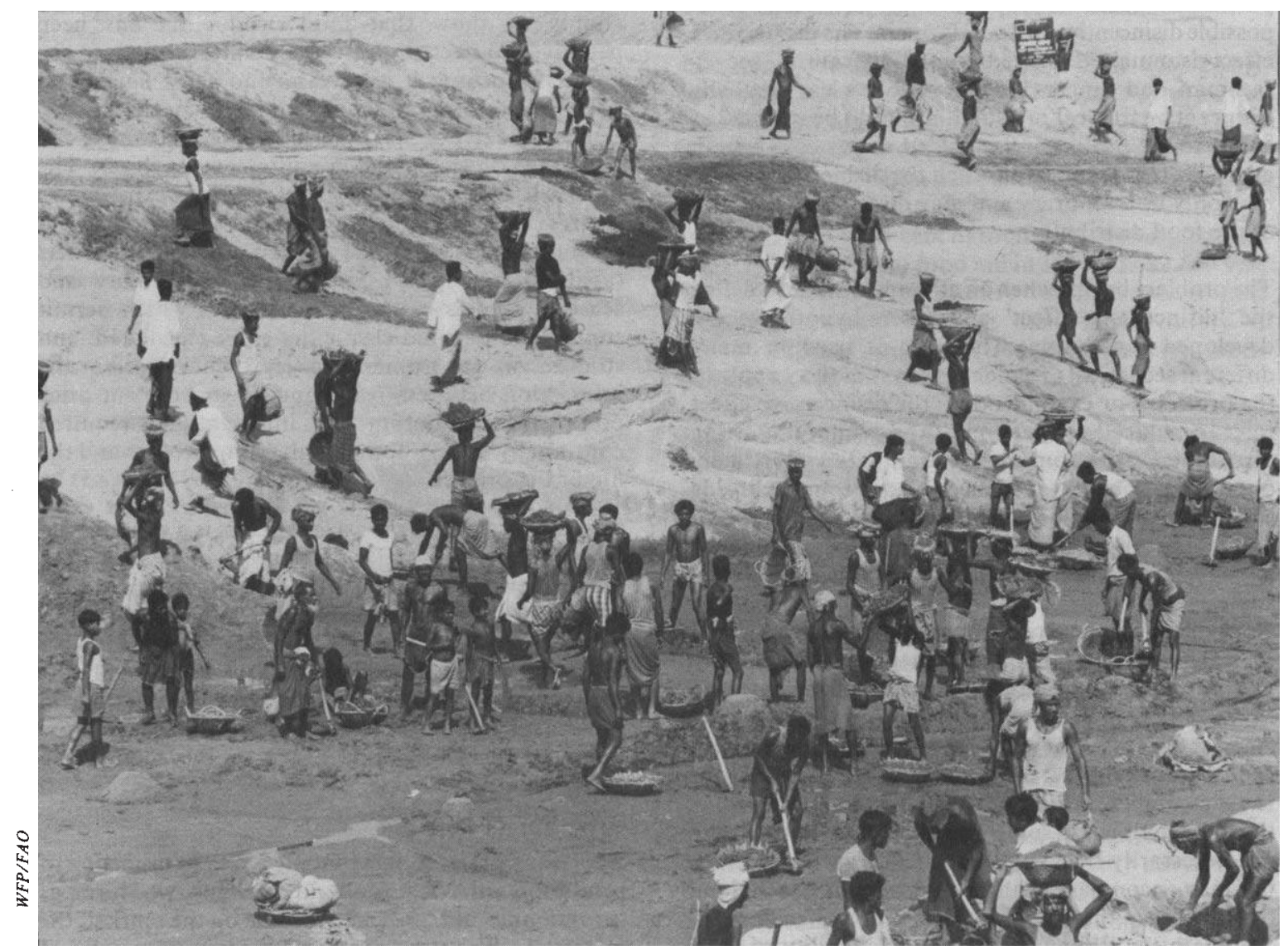

Can food for work projects, like this one in Bangladesh, undermine local food production? 
over time built into the project. Given that both characteristics are subject to many influences which may be outside the scope of the project itself, it will also be important to relate any changes in the population affected by the project to the direct actions of the project, usually by comparing a sample in the project area with a matched sample outside it. Once the size of the benefits has been established, it is possible to value them for inclusion in a more general social cost-benefit analysis. The data problem can be simplified by working with samples and making selective studies of the nutrition situation and the local labour market. In both cases, however, it will be necessary to take seasonal factors into account [Chambers et al 1979] and to consider not only average figures but also disaggregated data within individual families. All this may require longitudinal studies which are unlikely to be available to the project authorities and which therefore may have to be organised explicitly at the time of project preparation.

The second major indirect effect, which applies particularly to food for work projects, is that of possible disincentives to local farmers. The disincentive effect is much discussed in the literature [see eg Isenman and Singer 1977] and it is clear that any disincentive to local production should be counted as a cost to the project and included in any cost-benefit analysis. This is true even when the disincentive effect may only be temporary and may disappear at the end of the food distribution.

The problem begins when an attempt is made to define the 'disincentive effect' and when hypotheses are developed for testing. The term is used in many different senses, all of which may in some way apply to the project. For example, does the disincentive effect refer to reduced production of the commodity being distributed, or of some other commodity which may or may not substitute for the food aid commodity? Is the disincentive to be considered as a seasonal or an annual phenomenon? As a local or a regional one? As a temporary or a permanent one? And is it caused by some effect on price, by a reduction of incentives working through government policy, or by some direct effect on the labour force in the area? These may all be important questions that require investigation.

At least five different ways can be imagined in which a food for work project might cause a local disincentive. It may compete for labour with local agriculture so that production is in some way affected (the effect may not necessarily be a simple reduction in production, but may encompass changes in production technique or a change in the cropping pattern on typical farms). Alternatively, it may be that the availability of food for work discourages local farmers from planting subsistence crops so that they remain idle for part of the year and become dependent on food aid. A third possibility is that because of the availability of food aid, participants purchase less food on the local market than they otherwise would have done, so that prices fall and producers respond by cutting output. Alternatively, in a fourth variant, food for work participants may sell some of the food on the local market so that again prices and production are negatively affected. In both these cases the products which are affected may or may not be complete substitutes for the food aid commodity. Finally, in a fifth variant, production may be negatively affected because of some disincentive to government to procure locally or to invest in agriculture [see Jackson 1982, especially chapters 3 and 8].

It is not certain that any of these effects will occur. The point, however, is that they are extremely complex to measure, because they are likely to occur in complex rural societies in which the markets for labour and food are closely integrated with social interrelationships [Harriss 1982]. Furthermore, it is not enough simply to show that food production has been negatively affected: for policy intervention to be correctly focused it is necessary to show how it has been affected and precisely what the mechanism is. Each of the five scenarios briefly described above can be broken down and data requirements spelt out. The data will include household income and expenditure figures (disaggregated by social class, commodity and season); analyses of the labour and food markets (again disaggregated by activity, commodity and season); studies of market structures which permit supply and demand elasticities to be calculated; and studies of government policy which assess the interaction between, for example, government price policy and total output. This information is required continually during both the planning process and the life of the project.

It is important to emphasize that this is a summary of the data base required for a rigorous analysis. It is in fact, in several important respects, an oversimplified list, since it excludes economies and diseconomies which occur outside the project area. Possible incentive or disincentive effects occuring at the regional or national level as a result of project food aid flows have not been discussed, but would need to be taken into consideration in any serious monitoring and evaluation exercise.

\section{Programme food aid}

Food for work accounts for only a small proportion of total food aid. Most food aid, perhaps two thirds, is 'programme' aid, provided for sale on the market, the effects of which, though probably fewer than those of project aid, are very much harder to measure. 
The problems were hinted at in Section I which examined the difficulties inherent in the concept of the 'counterpart fund'. In order to assess the growth effect, and to study such negative aspects as the possible disincentive effect of food aid, it would normally be necessary to make a detailed study not only of the government's policy towards the agricultural sector, but also of its general development effort. Many studies have shown that government policy is a key element determining whether or not food aid has a positive effect [Clay and Singer 1982:39]; the difficulty is that present government policy has to be compared with an estimate of what government policy would have been in the absence of food aid, and this is of course speculative. It is for this reason that complex econometric models are of limited usefulness because they fail to provide more than an analysis of the historical association between food aid deliveries and certain aspects of food production. They do not explain what government might have done to increase food production had food aid not been available, nor do they deal with the political and institutional complexities of the trade-off between different government expenditures [however, see Hall 1980].

One solution is to lay down the expected effects of food aid before it is delivered, a means favoured by those who advocate linking food and other aid to the development of a 'food strategy' [European Parliament 1979, European Communities Commission 1980]. In this scenario food aid is provided in support of clearly defined policy and institutional changes designed to increase a recipient country's food security. Given that the policy changes required have been spelt out in sufficient detail, it is possible to monitor both their adoption and their impact over the life-time of the food aid proposal. This, of course, imposes considerable monitoring requirements on both donor and recipient. It is important to note that monitoring of this kind has hardly ever been carried out in the context of food aid programmes and there is little experience of what kind of field organisation might be required.

It is clear that, if a programme encompasses various types of food aid, impact assessment will require monitoring of many aspects of the recipient country's development planning and development achievements. It might be thought that national statistics are more easily available than data for smaller project assessment; but it should be remembered that the quality of statistics in developing countries often leave much to be desired, especially in the food sector [Lele and Candler 1978].

Given the complexities, the important question is not whether impact assessment is possible (it is an essential ingredient of properly managed food aid programmes) but of how it should be carried out. It is to this problem that we now turn.

\section{Designing an Operational Monitoring and Evaluation System for Food Aid}

The first point to make is that monitoring and evaluation systems will have to be built from scratch in most cases: at present very few food aid programmes, if any, go beyond the kind of casual evaluation that was described in the Introduction.

A second general point is that food aid donors cannot set up efficient monitoring and evaluation systems on their own. They do not control the data and they do not have the kind of access to rural areas that is needed to obtain it. Efficient monitoring and evaluation ought to be as much in the interest of the recipient as of the donor, and the priority for the donor should therefore be to build indigenous capacity for it, with, where necessary, technical and financial assistance.

Financial assistance is important. Just how costly monitoring and evaluation will be will depend on the type of food aid, the pre-availability of information and the complexity of the assessment required. But as a rough guide, Clayton has quoted IBRD figures to the effect that total monitoring and evaluation costs may be as high as 4.5 per cent of total project cost [Clayton 1981:9]. The value of food aid in 1980 was $\$ 2,600 \mathrm{mn}$, exclusive of all in-country administrative and supporting costs, so that this might imply a monitoring and evaluation budget (in cash not food) in excess of $\$ 117 \mathrm{mn}$.

A number of principles should be taken into account in designing the pilot monitoring systems. In the first place a certain degree of selectivity will obviously be necessary: it may be possible to select certain representative countries for regular monitoring and evaluation in a global system; it may be desirable to restrict impact assessment to certain selected issues; or to concentrate on food aid activities over a certain size. The aim is to reduce the size of the monitoring and evaluation exercise without sacrificing its systematic and planned nature. It is important to be sure, however, that the items studied are representative of some wider programme or population: what is being suggested is essentially a systematic 'case-study' approach (as opposed to the unsystematic approach described in Section I), which has many advantages but some recognised difficulties [Casley and Lury 1981]. Clearly any case study programme should be carefully and systematically planned to avoid adding to the haphazard nature of the existing opus. 
A related point concerns the relative importance of the topics selected for monitoring and evaluation. If a monitoring and evaluation system cannot encompass the whole range of effects that would normally be required to measure comprehensive impact, care must be taken to select the most important issues for study. A chosen model should predict what the most important effects are likely to be, and a simple monitoring system should trace any actual deviation from this. For example, it might be decided that, in a particular case, the local disincentive effect will probably be small and that it is not worth the likely expenditure of tracing it. But 'minimal monitoring' should be built into the system so that if in the event the local disincentive does turn out to be important, more resources can be switched into that field.

The step by step procedure might be adopted as a second general principle in monitoring and evaluation. It may make sense to devise a system which moves from the fairly general and superficial to the more specific and detailed as particular problem areas develop. In practice a system could be devised which builds a simple, conceptual model and carries out an initial cost-benefit analysis to identify the likely magnitude and direction of the changes resulting from food aid. A fairly widespread network of monitoring points could be established, not to provide detailed data in the first instance, but to signal the appearance of factors requiring closer scrutiny. The system would then have the resources to concentrate in greater detail on these items and to propose remedial action.

If we match this procedure to the food for work project analysed above, what might be required initially is a detailed ex ante cost-benefit study at both the private and social level, capturing the direct and indirect, internal and external costs and benefits of the project. It would be normal for the first run of the cost-benefit analysis to be complemented by a series of sensitivity analyses to identify the likely effect on overall profitability of changes in important parameters. This preliminary stage would require a good deal of base line data collection, but the data effort might be reduced in a second stage as project implementation began. It might be sufficient to measure key prices in the markets for labour and food, and to build on to the regular monitoring of project operation a skeletal system for measuring the direct benefits of the project. Only if the analysis of this data indicated a problem, would a full scale study of the disincentive effects or of the direct impact of the project be carried out during project operation. At the end of the project a full-scale evaluation could be organised, building on the initial data collected and on the skeletal monitoring system in place during the life of the project and collecting further data as necessary. If special 'issue studies' had been carried out, these would obviously be an important contribution to the final evaluation.

To the two principles of selectivity and a step by step approach can be added a third, which is the desirability of using data-economising methods. A considerable literature now exists on what is known as 'rapid rural appraisal' (RRA): assessment of the situation in rural areas without resort to the traditional and often cumbersome technique of the large scale physical or socio-economic survey [IDS 1981; Pearce and Jones 1981]. It is argued that a slight loss of accuracy is more than compensated for by greater speed and reduced cost of using RRA techniques. They include data collection by 'quick and dirty' surveys, the use of proxy variables which are easier to collect than traditional measures and the mobilisation of alternative sources of information, not least those supplied by farmers themselves. This methodology avoids main road bias, dry season bias, capital city bias and other biases which often appear in casual monitoring and evaluation exercises [Chambers 1980a, 1980b].

In all cases, it is evident that both a staff and a budget are required for monitoring and evaluation; that the importance of this for food aid planning be recognised, and that there be competent leadership in the field with access to policy makers. Furthermore, it is apparent that the particular characteristics of a monitoring and evaluation system will depend on factors in each individual country, and that no general, a priori design can be suggested. This does not mean that there should not be a design: it is necessary for the system to extend beyond the boundaries of individual recipient countries to embrace the programming of food aid as a whole. This is essential if the global, or donor-end, policy decisions are to be identified and the necessary data provided for improved decisions to be made.

\section{Conclusion}

This article has stressed the difficulty of resolving any debates on, or improving any form of food aid management without much closer attention to the impact of food aid programmes. It has, however, been argued that the impact cannot be measured casually, building on inadequate ex post evaluation. Rather, a comprehensive impact assessment system is required, in which the questions to be asked are identified at an early stage of project preparation and in which resources are provided for those questions to be answered during the lifetime of the project.

A system for monitoring and evaluating the impact of food aid will face a wide range of issues. This is inevitable given the complex effect of food aid, the 
diverse forms that it can take and the many types of recipient country into which it is injected. The article has shown that the information requirements for comprehensive impact assessment will be large and costly, and that, given the rudimentary character of data collection organisations in many developing countries and the unreliability of statistics, extra resources will have to be found.

However, there may be ways to reduce the financial burden: systems should be purposively selective; they should adopt a step by step approach; and they should make the greatest possible use of rapid appraisal techniques, especially in rural areas. Nevertheless, attempts to simplify the monitoring and evaluation task should not eclipse the need for an integrated, global system and for decisions about data limitation to be made explicit.

The way forward can now be discerned. Donors and recipients should recognise that the monitoring and evaluation function in food aid programmes has been neglected and should match this recognition by a commitment of will and money. It will then be necessary to set up some case studies of countries at different levels of development and with different types of food aid programme, and consider what monitoring and evaluation system would be both appropriate and feasible. The implications of the results for programme-wide, donor-level monitoring and evaluation systems should also be considered. It is only by studying the requirements of country case studies in detail that the problems inherent in setting up improved systems will become apparent.
It is clear, however, even at this stage, that there will be a cost to the donor and possibly to the recipient in setting up improved systems; and even if the financial cost to the recipient can be carried by the donor, there will be a cost in terms of scarce personnel, especially in rural areas. For this reason, there is a great deal to be said for greater donor coordination, not only in obtaining information in the short run but also in building up indigenous research capacity in the recipient countries. Some kind of inter-agency task force may be appropriate, perhaps based on the international agencies where recipient countries also have a voice: the Committee on Food Aid and the World Food Programme might be the most appropriate vehicles, although it would be important to achieve close cooperation with other major donors such as the EEC and the United States.

But whatever the form of action, let it be agreed that something must be done, and done as quickly as possible. The multiplication of one-off evaluation visits which has become such a feature of the development business in general is particularly damaging in the food aid field: it is a costly, ineffective and inappropriate way to work. Impact assessment has for too long played a bit part on the food aid stage: it is time it saw its name in lights.

For references see page 61 .

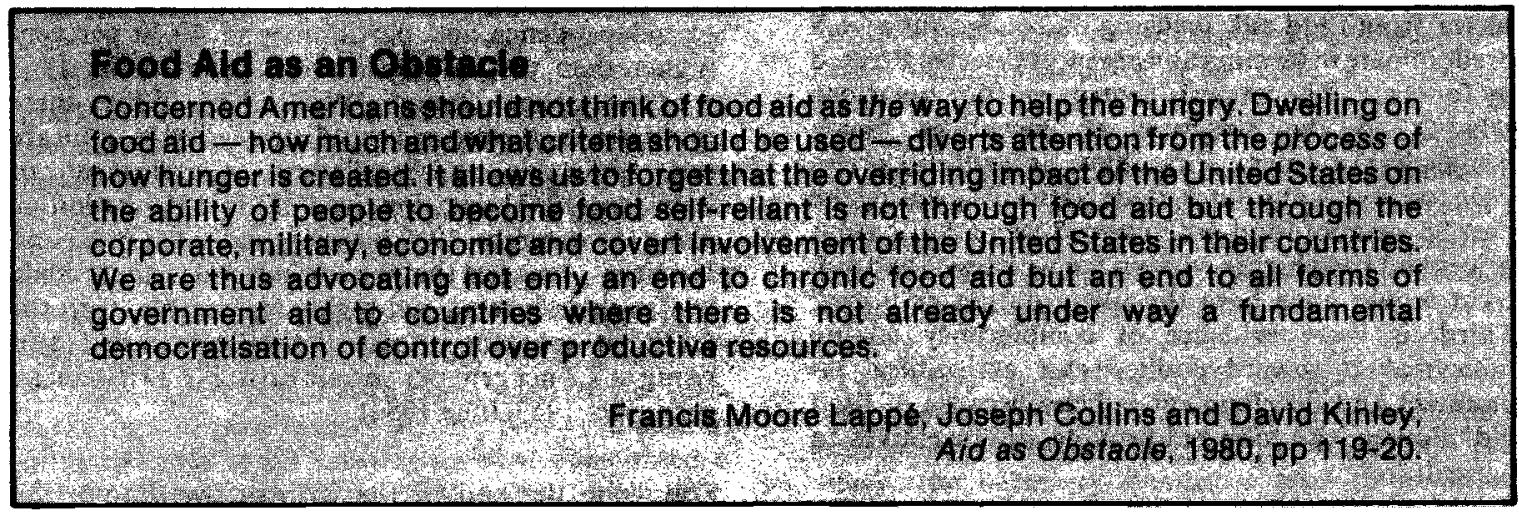

